Biochimica et Biophysica Acta, 620 (1980) 410-417

(C) Elsevier/North-Holland Biomedical Press

BBA 57679

\title{
DOES DE NOVO SYNTHESIS OF LYSOPHOSPHATIDYLCHOLINE OCCUR IN RAT LUNG MICROSOMES?
}

\author{
A.J. AARSMAN and H. VAN DEN BOSCH \\ Laboralory of Biochemistry, Padualaan 8, 3584 CII Utrecht (The Netherlands)
}

(Received May 12th, 1980)

Key words: Lysophosphatidylcholine synthesis; CDPcholine; Phosphatidylcholine; Pulmonary surfactant; (Rat lung microsome)

\section{Summary}

Incubation of rat lung microsomes with $\mathrm{CDP}\left[\mathrm{Me}^{14} \mathrm{C}\right]$ choline resulted in formation of radioactive lysophosphatidylcholine and phosphatidylcholine. Evidence is provided which suggests that lysophosphatidylcholine formation cannot be ascribed completely to phospholipase A degradation of phosphatidylcholine. Lysophosphatidylcholine production can be stimulated by addition of monoacylglycerol or diacylglycerol. It is suggested that diacylglycerol is partly hydrolyzed to monoacylglycerol and subsequently converted to lysophosphatidylcholine. A direct transfer of phosphocholine from CDPcholine to monoacylglycerol is demonstrated by equimolar incorporation of 1(3)-[9,10$\left.{ }^{3} \mathrm{H}_{2}\right]$ palmitoylglycerol and phospho $\left[\mathrm{Me}^{14} \mathrm{C}\right]$ choline into lysophosphatidylcholine.

\section{Introduction}

Lung function depends upon the presence in the alveolar lumen of a unique lipid-protein complex known as pulmonary surfactant. The major surface active component in this surfactant is 1,2-dipalmitoyl-sn-glycero-3-phosphocholine $[1,2]$, the synthesis of which has attracted much attention (see Refs. $3-5$ for reviews). It is generally believed that de novo synthesis of phosphatidylcholine in lung produces monoenoic- and dienoic species with primarily palmitate at the $s n-1$-position $[6,7]$. Two pathways are thought to contribute to the remodelling of these species into fully saturated phosphatidylcholine, i.e. acyl-CoA dependent acylation of lysophosphatidylcholine [8] and transacylation between two molecules of lysophosphatidylcholine $[9,10]$. Both pathways require lysophosphatidylcholine as substrate. This compound can be formed by the action of phospholipases $A_{2}$ reported to be present in lung [11-13] or can 
be taken up from the circulation [9]. Phospholipase action on diacylglyerophospholipids has long been thought to represent the only pathway for lysoglycerophospholipid formation. A novel pathway involving the direct transfer of phosphocholine from CDPcholine to monoacylglycerol was recently proposed to occur in microsomes of chicken embryo fibroblasts [14]. The alternative possibility, that the lysophosphatidylcholine was formed by the action of phospholipases A was discounted by these investigators, but no experimental data were shown to support this conclusion. In addition, no data were provided to show increased lysophosphatidylcholine synthesis upon addition of monoacylglycerol or a direct conversion of labelled monoacylglycerol into lysophosphatidylcholine. In the present paper we provide evidence which indicates that lung microsomes can indeed synthesize lysophosphatidylcholine from monoacylglycerol and CDPcholine.

\section{Materials and Methods}

\section{Materials}

Cytidine $5^{\prime}$-diphospho $\left[\mathrm{Me}^{14} \mathrm{C}\right]$ choline (spec. radioact. $60.9 \mathrm{Ci} / \mathrm{mol}$ ) was obtained from Radiochemical Centre, Amersham, U.K. Unlabelled CDPcholine was purchased from Sigma, St. Louis, MO, U.S.A. Palmitic acid was obtained from J.T. Baker Chemicals N.V., Deventer, Holland, whereas $\left[9,10-{ }^{3} \mathrm{H}_{2}\right]$ palmitic acid was bought from NEN Chemicals, Dreieich, F.R.G. Diisopropylfluorophosphate was a product from Aldrich Europe, Beerse, Belgium.

\section{Synthesis of substrates}

Palmitoylchloride was prepared according to Daubert et al. [15]. 1(3)-Monopalmitoylglycerol was synthesized by acylation of excess glycerol with palmitoylchloride in dry tetrahydrofuran and pyridine. The monoacylglycerol was purified on silica $G$ thin-layer plates which were developed in diethyl ether/ hexane $(75: 25, \mathrm{v} / \mathrm{v})$. The radioactive monopalmitoylglycerol had a specific radioactivity of $14400 \mathrm{dpm} / \mathrm{nmol}$.

1,2-Diacyl-sn-glycerol was prepared from egg phosphatidylcholine with phospholipase C from Clostridium welchii (enzyme kindly donated by Dr. B. Roelofsen). The ${ }^{14} \mathrm{C}$-labelled diacylglycerol was prepared in the same way from 1-acyl-2-[1-14 C]oleoyl-sn-glycero-3-phosphocholine (spec. radioact. $3500 \mathrm{dpm} /$ $\mathrm{nmol}$ ), which was prepared as described by Waite and van Deenen [16].

\section{Isolation of microsomes}

Lungs from two rats were homogenized with a Potter-Elvehjem homogenizer

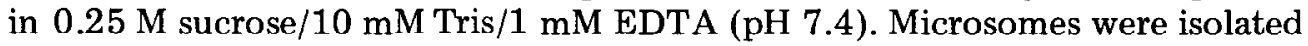
according to established procedures. The microsomal fraction was resuspended in the same buffer. Microsomes treated with diisopropylfluorophosphate ( $3 \mu \mathrm{mol} / \mathrm{mg}$ protein) for $30 \mathrm{~min}$ at $30^{\circ} \mathrm{C}$ are designated DP-microsomes. Protein was determined as described by Lowry et al. [17].

\section{Incubation and product analysis}

Incubation conditions are described in the legends to the respective figures and tables. Optimal diacylglycerol $(8 \mathrm{mM})$ and CDPcholine $(0.26 \mathrm{mM})$ con- 
centrations for cholinephosphotransferase assays were taken from reported studies on rat lung microsomes [23]. The initial experiments described in table I used sub-optimal amounts of CDPcholine. The latter was used at the highest specific radioactivity available to establish that formation of radioactive lysophosphatidylcholine took place. Reactions were stopped by addition of 3 vols. of $\mathrm{CHCl}_{3} / \mathrm{CH}_{3} \mathrm{OH}(1: 2, \mathrm{v} / \mathrm{v})$, to initiate extraction of the lipids according to Bligh and Dyer [18].

Neutral lipids were separated on silica G plates by development with light petroleum ether/diethyl ether/formic acid $(60: 40: 1.5, \mathrm{v} / \mathrm{v})$. Phospholipids were fractionated on silica $\mathrm{H}$ thin-layer plates which were run in chloroform/ methanol/acetic acid/water $(100: 50: 16: 8, \mathrm{v} / \mathrm{v})$.

Radioactive spots in single-labelled experiments were scraped immediately into scintillation vials containing toluene scintillation fluid/Triton X-100/water $(2: 1: 0.2, \mathrm{v} / \mathrm{v})$. In double-labelled experiments the radioactive compounds were eluted from the silica gel with $\mathrm{CHCl}_{3} / \mathrm{CH}_{3} \mathrm{OH}(20: 80$, v/v). The organic solvent was evaporated, the residue dissolved in a small volume of $\mathrm{CH}_{3} \mathrm{OH}$ and transferred into scintillation vials containing toluene scintillation fluid (5 g PPO and $0.25 \mathrm{~g}$ dimethyl POPOP per liter). Radioactivity measurements were carried out in a Packard Tricarb model 3320 liquid scintillation spectrometer.

\section{Results and Discussion}

Table I shows that lung microsomes, when incubated with $\mathrm{CDP}\left[\mathrm{Me}-{ }^{14} \mathrm{C}\right]$ choline, produce both phosphatidylcholine and lysophosphatidylcholine. The formation of these products is not inhibited by pretreatment of the microsomes with diisopropylfluorophosphate. In contrast, addition of $10 \mathrm{mM} \mathrm{Ca}^{2+}$ completely abolishes formation of radioactive phospholipids. For phosphatidylcholine synthesis this result is in agreement with findings of Kennedy and Weiss obtained with rat liver microsomes [19]. Addition of monoacylglycerol results in an approx. 5-fold increase in lysophosphatidylcholine production and at the same time seems to inhibit phosphatidylcholine synthesis somewhat. As expected a large increase in phosphatidylcholine synthesis is observed upon addition of 1,2-diacylglycerol. However, an increased synthesis of lysophosphatidylcholine is also observed under these conditions. Several possibilities can be raised to explain these findings. First, the 1,2-diacylglycerol either contains sufficient monoacylglycerol to stimulate lysophosphatidylcholine formation or is partly converted by microsomal lipase(s) into monoacylglycerol during the course of the incubation. Secondly, increased formation of phosphatidylcholine could give rise to enhanced lysophosphatidylcholine production through the action of microsomal phospholipase(s) A. The following experiments were disigned to differentiate between these possibilities.

Phospholipase $A_{2}$ activity has been described in rat lung microsomes $[11,13]$. Although the enzyme was reported to have an absolute requirement for $\mathrm{Ca}^{2+}$ when assayed with exogenous phosphatidylethanolamine [11] and $\mathrm{Ca}^{2+}$ was not present in the incubations in which we found lysophosphatidylcholine formation, it was felt necessary to investigate whether lysophosphatidylcholine production could be ascribed to endogenous microsomal phospholipase activity. Microsomes, pretreated with diisopropylfluorophosphate were labelled by 
TABLE I

\section{SYNTHESIS OF ACYLGLYCEROPHOSPHOCHOLINES IN RAT LUNG MICROSOMES}

The incubation mixture contained $15 \mathrm{mM}$ Tris-HCl buffer (pH 7.4), $20 \mathrm{mM} \mathrm{MgCl} 2,1 \mathrm{mM}$ EDTA, $17 \mu \mathrm{M}$ CDP $\left[M e^{-14} \mathrm{C}\right]$ choline (spec. act. $125000 \mathrm{dpm} / \mathrm{nmol}$ ) and $250 \mu \mathrm{g}$ microsomal protein. Additions were present in the following final concentrations: $\mathrm{Ca}^{2+}, 10 \mathrm{mM}$; monoacylglycerol (MG), $1 \mathrm{mM}$ or diacylglycerol (DG), $8 \mathrm{mM}$ in $0.01 \%(\mathrm{w} / \mathrm{v})$ Tween 20 . Incubation was done for $30 \mathrm{~min}$ at $37^{\circ} \mathrm{C}$ in a total volume of $0.5 \mathrm{ml}$. Data from one experiment, representative of three experiments showing similar results, are given. Abbreviations: n.d., not detectable; DP-microsomes, microsomes treated with diisopropylfluorophosphate.

\begin{tabular}{llcc}
\hline Enzyme & Addition & $\begin{array}{l}\text { Lysophosphatidylcholine } \\
\text { (pmol) }\end{array}$ & $\begin{array}{l}\text { Phosphatidylcholine } \\
\text { (pmol) }\end{array}$ \\
\hline Microsomes & none & 12 & 304 \\
& Ca & n.d. & n.d. \\
& MG & 80 & 220 \\
DG-microsomes & DG & 80 & 2440 \\
& none & 22 & 312 \\
& MG & 100 & 246 \\
& DG & 118 & 2340 \\
\hline
\end{tabular}

incubation with $\mathrm{CDP}\left[\mathrm{Me}-{ }^{14} \mathrm{C}\right]$ choline in the presence or absence of added 1,2diacylglycerol and reisolated by centrifugation. The prelabelled microsomes were resuspended in the same media in which the labelling was carried out, except that non-radioactive CDPcholine was used. Further incubation was done either without addition, with $20 \mathrm{mM} \mathrm{Ca}^{2+}$ or with $50 \mathrm{mM}$ EDTA. As can be seen in Table II lysophosphatidylcholine contained $4.7-4.9 \%$ of the ${ }^{14} \mathrm{C}$-radioactivity in the lipid extract of microsomes incubated with 1,2-diacylglycerol. In microsomes prelabelled in the absence of added 1,2-diacylglycerol this value amounted to $6.2-6.6 \%$. These values increase somewhat during further incubation, especially when $\mathrm{Ca}^{2+}$ is present. This suggests that phospholipases may indeed contribute to lysophosphatidylcholine formation. However, increases

\section{TABLE II}

\section{INCUBATION OF PRELABELLED MICROSOMES}

Microsomes, pretreated with diisopropylfluorophosphate, were incubated with $\mathrm{CDP}\left[\mathrm{Me}-{ }^{14} \mathrm{C}\right] \mathrm{choline}$ in the presence or absence of 1,2-diacylglycerol as described in Table $I$. The microsomes were isolated by centrifugation ( $30 \mathrm{~min}$ at $150000 \times \mathrm{g}$ ) and resuspended in the same media in which the labelling was done, except that CDP $\left[\mathrm{Me}^{14} \mathrm{C}\right]$ choline was replaced by CDPcholine. The prelabelled microsomes were incubated for the indicated time periods at $37^{\circ} \mathrm{C}$ either with no addition, with $20 \mathrm{mM} \mathrm{Ca}{ }^{2+}$ or with 50 MM EDTA.

\begin{tabular}{|c|c|c|c|c|c|c|}
\hline \multirow{3}{*}{$\begin{array}{l}\text { Incubation } \\
\text { time } \\
\text { (min) }\end{array}$} & \multicolumn{6}{|c|}{ Percentage ${ }^{14} \mathrm{C}$ label in lysophosphatidylcholine } \\
\hline & \multicolumn{3}{|c|}{ without 1,2-diacylglycerol } & \multicolumn{3}{|c|}{ with 1,2-diacylglycerol } \\
\hline & $\begin{array}{l}\text { no } \\
\text { addition }\end{array}$ & $\mathrm{Ca}^{2+}$ & EDTA & $\begin{array}{l}\text { no } \\
\text { addition }\end{array}$ & $\mathrm{Ca}^{2+}$ & EDTA \\
\hline 0 & 6.6 & 6.6 & 6.2 & 4.9 & 4.7 & 4.7 \\
\hline 30 & 6.6 & 7.4 & 6.8 & 5.9 & 6.6 & 5.4 \\
\hline 60 & 6.4 & 7.7 & 6.8 & 6.5 & 7.6 & 5.9 \\
\hline 100 & 6.6 & 8.6 & 7.2 & 6.9 & 8.8 & 6.8 \\
\hline
\end{tabular}


observed in the first $30 \mathrm{~min}$ of the incubations without additions, i.e. exactly the same conditions as during the prelabelling, are much lower than the lysophosphatidylcholine labelling attained during the prelabelling. This suggests that formation of lysophosphatidylcholine during the prelabelling experiment cannot be explained completely by hydrolysis of phosphatidylcholine by phosphoslipases.

We then investigated whether the increased formation of lysophosphatidylcholine, observed upon addition of 1,2-diacylglycerol (Table I), could be ascribed to incorporation of phosphocholine into monoacylglycerol produced by microsomal lipases from the added 1,2-diacylglycerol. Lipases are known to be present in lung tissue [20-22]. When microsomes were incubated with 1 -acyl-2[1-14 $\mathrm{C}]$ oleoylglycerol a rapid decrease in diacylglycerol was observed (Fig. 1). The label lost from diacylglycerol was quantitatively recovered in free fatty acid and monoacylglycerol, presumably as a result of the action of a diacylglycerol lipase and a monoacylglycerol lipase. The latter enzyme appears to be more sensitive to inhibition by disopropyfluorophosphate. The limited hydrolysis of diacylglycerol observed in microsomes pretreated with diisopropylfluorophosphate gave rise to the exclusive formation of monoacylglycerol with no production of free $\left[{ }^{14} \mathrm{C}\right]$ oleate. Due to the fact that monoacylglycerol formation could not be completely prevented in incubations with diacylglycerol, the stimulation of lysophosphatidylcholine production observed upon diacylglycerol addition could indeed be the result of this monoacylglycerol formation. This would require the direct transfer of phosphocholine from CDPcholine to monvacylglycerol. More direct evidence for the occurrence of this pathway was obtained in experiments with monoacylglycerol as substrate. Fig. 2 shows the effect of increasing monoacylglycerol concentrations on the incorporation of phosphocholine from CDPcholine into lysophosphati-
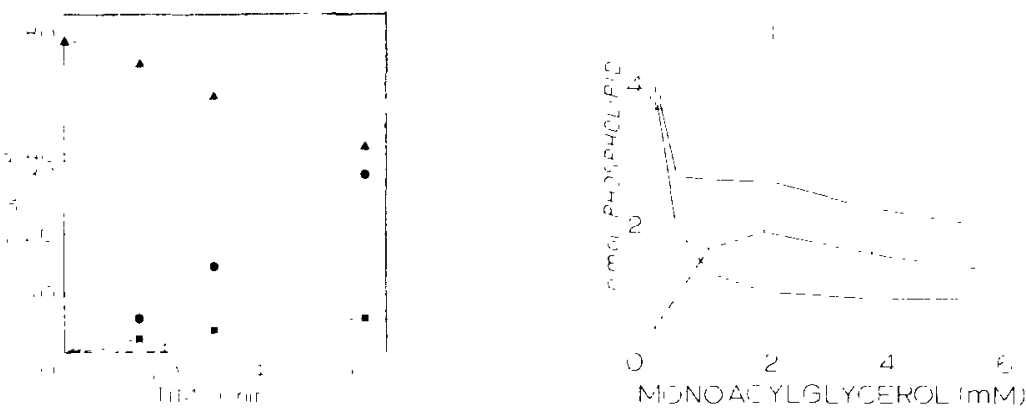

Fig. 1. Fate of diacylglycerol upon incubation with rat lung microsomes. 1-Acyl-2-[1.14 C ]oleoyl-sn-glycerol (0.33 $\mathrm{mM}$ ) was incubated with $200 \mu \mathrm{g}$ microsomal protein in $25 \mathrm{mM}$ Tris-HCl (pH 7.5$), 10 \mathrm{mM}$ $\mathrm{MgCl}_{2}$ and $5 \mathrm{mM} \mathrm{CaCl}_{2}$ in $0.01 \%$ (w/v) Tween 20 in a volume of $0.26 \mathrm{ml}$. Open symbols, diisopropylfluorophosphate-treated microsomes; closed symbols, untreated microsomes. gly cerol; $, \ldots . .-\bullet, \bullet$, fatty acld; $\square+\ldots .-\square, \square-\longrightarrow,-$, monoacylgly cerol.

Fig. 2. Effect of monoacylglycerol on formation of lysophosphatidylcholine and phosphatidylcholine in rat lung microsomes. Diisopropylfluorophosphate-treated microsomes (600 $\mathrm{\mu g}$ protein) were incubated in $25 \mathrm{mM}$ Tris- $\mathrm{HCl}(\mathrm{pH} 7.5), 10 \mathrm{mM} \mathrm{MgCl} 2,0.03 \%(\mathrm{w} / \mathrm{v})$ Tween 20 and $0.26 \mathrm{mM} \mathrm{CDP}\left[\mathrm{Me}^{-14} \mathrm{C}\right] \mathrm{choline}$ (spec act. $10000 \mathrm{dpm} / \mathrm{nmol}$ ) in a total volume of $0.4 \mathrm{ml}$ during $30 \mathrm{~min}$ at $37^{\circ} \mathrm{C}$. $\square \longrightarrow \square$. total glycerophosphocholines: the averages of two determinations. 

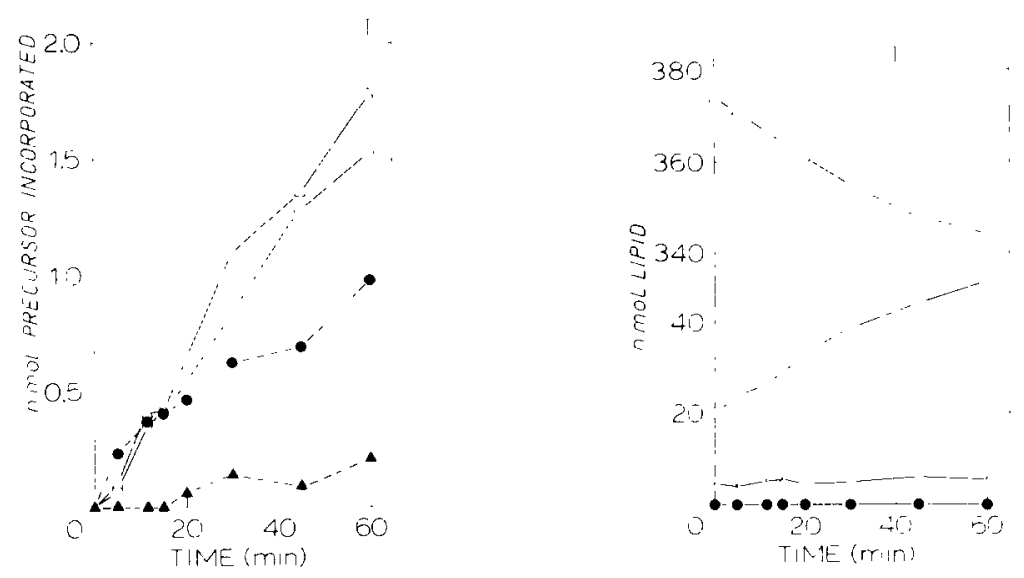

Fig. 3. Incorporation of $\left[{ }^{3} \mathrm{H}\right]$ monoacylgly cerol and phospho[ $\left[\mathrm{Me}^{14} \mathrm{C}\right] \mathrm{choline}$ into phospholipids of rat lung microsomes. Diisopropylfluorophosphate-treated microsomes (300 $\mathrm{g}$ protein) were incubated under the same conditions as described in Fig. 2, expect that $1 \mathrm{mM}\left[{ }^{3} \mathrm{H}\right]$ monoacylglycerol was present. Open symbols, lysophosphatidylcholine; closed symbols, phosphatidylcholine. $\triangle \longrightarrow \_\triangle, \Delta-\ldots-\ldots,{ }^{3} \mathrm{H}$ label and $\longrightarrow, \cdots . . . \cdot,{ }^{4} \mathrm{C}$ label.

Fig. 4. Fate of monoacylglycerol upon incubation with rat Iung microsomes. Incubation conditions as in Fig. 3. $-\longrightarrow$, triacylglycerol: $X-X$, diacylglycerol: $\bigcirc-O$, free fatty acid and $\Delta--\triangle$, monoacylglycerol.

dylcholine and phosphatidylcholine. Increasing concentrations of monoacylglycerol up to $2 \mathrm{mM}$ stimulate lysophosphatidylcholine formation, while at the same time inhibiting phosphatidylcholine synthesis. One explanation for this observation could be that lysophosphatidylcholine and phosphatidylcholine are synthesized by a single cholinephosphotransferase. Although it is tempting to conclude from Fig. 2 that monoacylglycerol is a substrate for lysophosphatidylcholine synthesis alternative explanations can still be provided, e.g. inhibition of cholinephosphotransferase and stimulation of phospholipase activities by the added monoacylglycerol would yield similar results. To show that monoacylglycerol is indeed incorporated into lysophosphatidylcholine, experiments were carried out with $1(3)-\left[9,10-{ }^{3} \mathrm{H}_{2}\right]$ palmitoylglycerol in the presence of $\mathrm{CDP}[\mathrm{Me}$ ${ }^{14} \mathrm{C}$ ]choline. As can be seen in Fig. 3 , within experimental error equimolar amounts of monoacylglycerol and phosphocholine were incorporated into lysophosphatidylcholine. The fact that phosphocholine incorporation is consistently $10-20 \%$ lower than monoacylglycerol incorporation is most likely

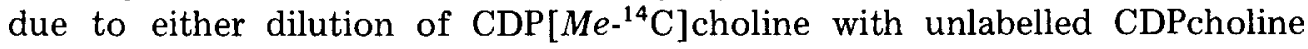
adhering to the microsomes or to a systematic error introduced in the determinations of the specific radioactivity of the precursors. During the first 15 min of the incubation, no ${ }^{3} \mathrm{H}$ label appears in phosphatidylcholine. The slight incorporation observed thereafter is presumably due to either acylation of $\left.{ }^{3} \mathrm{H}\right]$ lysophosphatidylcholine or endogenous lysophosphatidylcholine with $\left[{ }^{3} \mathrm{H}\right]$ palmitate (compare Fig. 4). Acylation of $\left[{ }^{3} \mathrm{H}\right]$ monoacylglycerol to diacylglycerol and subsequent conversion into phosphatidylcholine is less likely since no formation of diacylglycerol was detected (Fig. 4). Theoretically, the latter pathway (monoacylglycerol $\rightarrow$ diacylglycerol $\rightarrow$ phosphatidylcholine) could proceed without accumulation of the intermediary diacylglycerol and this pos- 
sibility cannot be excluded completely. However, the appearance of ${ }^{3} \mathrm{H}$ label in lysophosphatidylcholine cannot be explained by the action of a phospholipase A on phosphatidylcholine. At all time points the ${ }^{3} \mathrm{H} /{ }^{14} \mathrm{C}$ ratio in lysophosphatidylcholine is much higher than in phosphatidylcholine. Phospholipase A action on phosphatidylcholine would yield lysophosphatidylcholine with ${ }^{3} \mathrm{H} /{ }^{14} \mathrm{C}$ ratio equal to or lower than that in phosphatidylcholine. These considerations and the almost equimolar incorporation of $\left[{ }^{3} \mathrm{H}\right]$ monoacylglycerol and phospho $[\mathrm{Me}$ $\left.{ }^{14} \mathrm{C}\right]$ choline into lysophosphatidylcholine clearly demonstrated the feasibility of de novo synthesis of lysophosphatidylcholine.

Fig. 4 demonstrates that even in microsomes pretreated with diisopropylfluorophosphate some hydrolysis of $\left[{ }^{3} \mathrm{H}\right]$ monoacylglycerol still takes places. As mentioned above incorporation of the released $\left[{ }^{3} \mathrm{H}\right]$ palmitate into lysophosphatidylcholine could be partially responsible for the appearance of ${ }^{3} \mathrm{H}$ label in phosphatidylcholine. However, no formation of either diacylglycerol or triacylglycerol is observed.

Although the possibility of de novo synthesis of lysophosphatidylcholine in lung microsomes has been proven in vitro, it cannot yet be stated to what extent this reaction contributes to lysophosphatidylcholine formation in vivo.

In experiments comparable to those described in Table I but in the presence of saturating levels of CDPcholine $(0.26 \mathrm{mM})$ the addition of an equimolar mixture of monoacylglycerol and diacylglycerol $(7 \mathrm{mM}$ each) resulted in an about 20 -fold enhanced synthesis of both lysophosphatidylcholine and phosphatidylcholine (data not shown). Lysophosphatidylcholine contained about $6 \%$ of the ${ }^{14} \mathrm{C}$ radioactivity, irrespective of whether monoacylglycerol plus diacylglycerol was present or not. Thus, when both monoacylglycerol and diacylglycerol are present in excess there is still a large preference for phosphocholine incorporation into diacylglycerol. De novo synthesis of lysophosphatidylcholine is thus a minor pathway compared with de novo synthesis of phosphatidylcholine (compare Table I). Whether and to what extent these syntheses are influenced by the relative concentrations of monoacylglycerol and diacylglycerol in microsomal membranes remains to be determined in future work. Also, the relative importance of de novo synthesis of lysophosphatidylcholine in comparison to lysophosphatidylcholine formation by the action of microsomal phospholipases A cannot be evaluated at present. The experiments described in Tables I and II suggest that de novo synthesis could contribute considerably to lysophosphatidylcholine formation.

\section{References}

1 Goerke, .J. (1974) Biochim. Biophys. Acta 344, 241-261

2 King, R.J. and Clements, J.A. (1972) Am. J. Physiol. 223, 715-726

3 Van Golde, L.M.G. (1976) Am. Rev. Respir. Dis. 114, 977-1000

4 Frosolono, M.F. (1977) in Lipid Metabolism in Mammals (Snyder, F., ed.), Vol. 2, pp. 1-38, Plenum Press, New York

5 Ohno, K., Akino, T. and Fujiwara, T. (1978) in Reviews in Perinatal Medicine (Scarpelli, E.M. and Cosmi, E.V., eds.), Vol. 2, pp. 227-318, Raven Press, New York

6 Vereyken, J.M., Montfoort, A. and van Golde, L.M.G. (1971) Biochim. Biophys. Acta $260,70-81$

7 Sarzala, M.G. and van Golde, L.M.G. (1976) Biochim. Biophys. Acta 441, $423-432$

8 Lands, W.E.M. (1960) J. Biol. Chem. 235, 2233--2237

9 Akino, T., Yamazaki, I. and Abe, M. (1972) Tohoku J, Exp. Med. 108, 133-139

10 Brumley, G. and van den Bosch, H. (1977) J. Lipid. Res. 18, 523-532 
11 Garcia, A., Newkirk, J.D. and Mavis, R.D. (1975) Biochem. Biophys. Res. Commun. 64, 128-135

12 Ohta, M., Hasegawa, H. and Ohno, K. (1972) Biochim. Biophys. Acta 280, 552-558

13 Longmore, W.J., Oldenborg, V. and van Golde, L.M.G. (1979) Biochim. Biophys. Acta 572, 452-460

14 Edwards, R.G. and Blough, H.A. (1978) Virology 89, 314-317

15 Daubert, B.F., Fricke, H.H. and Longenecker, H.E. (1943) J. Am. Chem. Soc. 65, 2142-2144

16 Waite, M. and van Deenen, L.L.M. (1967) Biochim. Biophys. Acta 137, 498-517

17 Lowry, O.H., Kosebrough, N.J., Farr, A.L. and Randall, R.J. (1951) J. Biol. Chem. 193, 265-275

18 Bligh, E.G. and Dyer, W.J. (1959) Can. J. Biochem. Physiol. 37, 911-917

19 Kennedy, E.P. and Weiss, S.B. (1956) J. Biol. Chem. 222, 193-214

20 Hamosh, M. and Hamosh. P. (1975) Biochim. Biophys. Acta 380, 132-140

21 Wang, M.C. and Meng, H.C. (1975) Lipids 10, 721-725

22 Armstrong, H.J., Kuenzig, M.C. and Peltier, L.F. (1967) Proc. Soc. Exp. Biol. 124, 959-961

23 Possmayer, F., Duwe, G., Hahn, M. and Buchnea, D. (1977) Can. J. Biochem. 55, 609-617 